\title{
Briefing: Pyrolysis of natural gas to hydrogen: a key energy transition tool
}

1 Richard Clarke BSC (Hons), FIChemE

Senior Consultant, Climate \& ESG Solutions at Ortec Finance, London, UK and Rotterdam, the Netherlands

(corresponding author: richard.clarke@ortec-finance.com)

\author{
2 Alberto Abánades $M S c, P h D$ \\ Full Professor, ETSII-UPM, Universidad Politécnica de Madrid, Madrid, \\ Spain (Orcid:0000-0003-0179-5987)
}
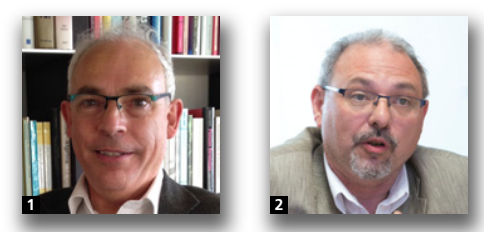

To achieve a low carbon dioxide $\left(\mathrm{CO}_{2}\right)$ energy future the fossil fuel industry must pivot to make zero-emissions hydrogen through an open, global collaboration. One track to this is 'pyrolysis' in which natural gas is split into 'white' hydrogen and carbon black. This avoids the need for a massive roll-out of carbon capture and storage sites as envisaged in natural gas reforming or 'blue' hydrogen schemes. The advantages of both options are needed to support longer-term efforts to move towards 'green' hydrogen where water is split into its elements. By leading the development of all these routes to hydrogen, the energy majors of today will be able to utilise their enormous resources, technical ingenuity and vast capital and lead the future of energy. With the COP26 climate conference just months away, the UK has a critical role in directing efforts to bring hydrogen to the fore both at home and abroad.

Fear of a planetary climate collapse promotes an understandable desire to keep fossil fuels buried underground and rapidly convert the world's economy from hydrocarbon to low carbon dioxide energy. To reach that urgent ambition requires hydrogen, and masses of it (Nuttall and Bakenne, 2020), but time is running out (Meinshausen et al., 2009). Global warming exceeds $1{ }^{\circ} \mathrm{C}$ and the 2015 Paris Agreement goal of limiting the rise to $1.5-2^{\circ} \mathrm{C}$ is in danger of being lost. While wind and solar energy costs have fallen steadily, analyst McKinsey says the 'math is daunting' (Henderson et al., 2020) if the target of net zero carbon dioxide emissions is to be reached by 2050 .

In the authors' view, the fossil fuel energy giants must now rise to a new challenge, to use their enormous resources, technical ingenuity and vast capital to produce fossil-sourced energy with near-zero releases of greenhouse gases. Such action would seal their fate - to be part of the future of energy.

Today's global efforts on carbon dioxide emissions reduction ('decarbonisation') are woefully insufficient and, all too often, they perilously require nature to be a kind of carbon banker. Very few analysts take into account a vast sea of hydrogen that can be won if only the link between fossil fuels and emissions is broken.
In the long run, water will be the main source of hydrogen but in the energy transition period, natural gas could play a major role provided the logistics are critically examined. The goal must be to develop all forms of clean hydrogen, at scale, through global alliances.

\section{Hydrogen too}

Last April, the UK's Department for Business, Energy and Industrial Strategy started recruiting staff to implement the UK's Net Zero 2050 plan - to roll out electric vehicle chargers, power storage and the digital infrastructure to make it all work (UK Government, 2020). Is hydrogen an also-ran? Until 2020, it seemed so, due to the success of solar and wind, offshore wind in particular.

Hydrogen's public relations is a challenge. To obtain low carbon dioxide or 'green' hydrogen requires the use of electrolysis, even though water is becoming a precious resource. Alternatively, if hydrogen comes from natural gas it is deemed to be 'grey', tainted by a sense that carbon dioxide emissions were obscured in early trials. Hydrogen bus roll-outs in cities have thus had a mixed reception. Yet WrightBus, a Northern Ireland company, has plans to make 3000 buses and convert $10 \%$ of the UK inventory to hydrogen. Road haulage fleets could run on hydrogen too. 
As electric cars gain market share the transport eggs must be placed in more than one energy basket.

For steel and glassmaking, the need for high-temperature heat makes hydrogen ideal. In California, an all-electric future looks like playing with fire: in 2019 Pacific Gas and Electric settled a US $\$ 13.5$ billion claim its pylons ignited forest fires that destroyed towns, killing many.

In home cooking and heating, hydrogen burns cleanly and, being carbon dioxide-free, hydrogen-fuelled boilers would take the pressure off still-elusive home insulation efficiency targets. The challenge now is to safely access all the hydrogen at present locked up in fossil fuels, to boost the transition to a world of interchangeable clean power and heat.

\section{Fossil's future}

Hydrogen is an exit strategy for the fossil fuel industry; it avoids the need to abandon vast reserves of gas and oil that, in practice, the world still needs. However, ClientEarth's litigation (ClientEarth, 2021) shows the industry the time has come to seriously up its game on fugitive emissions, pollution, safety and disclosure. Public trust has to be regained. Its hydrogen must be lilywhite. With oil, the future lies in a myriad of non-fuel products - the plastics, pharmaceuticals and chemicals that underpin modern life. Using microwaves, hydrogen and graphene precursors can be made from waste plastic. The Financial Times anticipates that peak oil production is near (Lewis, 2020).

\section{Unwelcome guest}

Hydrogen is labelled 'grey' if carbon dioxide is vented during its production, in a reformer, the main route to hydrogen today. If carbon dioxide is not to be released, it must be buried or used for example, for enhanced oil recovery. The Allam Fetvedt process (NETpower) aims to produce pure carbon dioxide in an energy plant that will cost no more than standard natural gas power facilities that, in any case, could run on hydrogen.

Environmentalists worry that buried carbon dioxide might leak out; yet, until recently, there has not been wide interest in carbon dioxide capture and storage (CCS). Columbia University's Julio Friedman notes just $0.1 \%$ of today's carbon dioxide emissions are captured (Resources Radio, 2020). Moreover, after a decade's work, the European Union (EU) had spent $€ 424$ million on CCS with little to show for it (Rathi, 2018). In the US, uptake of the $45 \mathrm{Q}$ tax break suggests there is limited appetite for firm action on CCS. Enticing schemes, such as biomass with carbon capture (BECCS) now look to be deeply flawed. Ongoing alarm over climate-changedriven tipping points makes it clear that the earth and atmosphere can no longer accommodate carbon dioxide on the faint promise of its future capture.
With 'blue' hydrogen the carbon dioxide is captured and with 'green' hydrogen only water and electricity are needed. To unblock the energy transition, say consultants Pöyry (Sarsfield-Hall and Under, 2019), fossil hydrogen must be recovered without producing carbon dioxide. How? By making 'white' hydrogen gas and carbon black, a vital feedstock for the future (Figure 1).

\section{Trial separation}

Pyrolysis literally means fire and separation. The urgency of the climate crisis has renewed interest in an alternate form

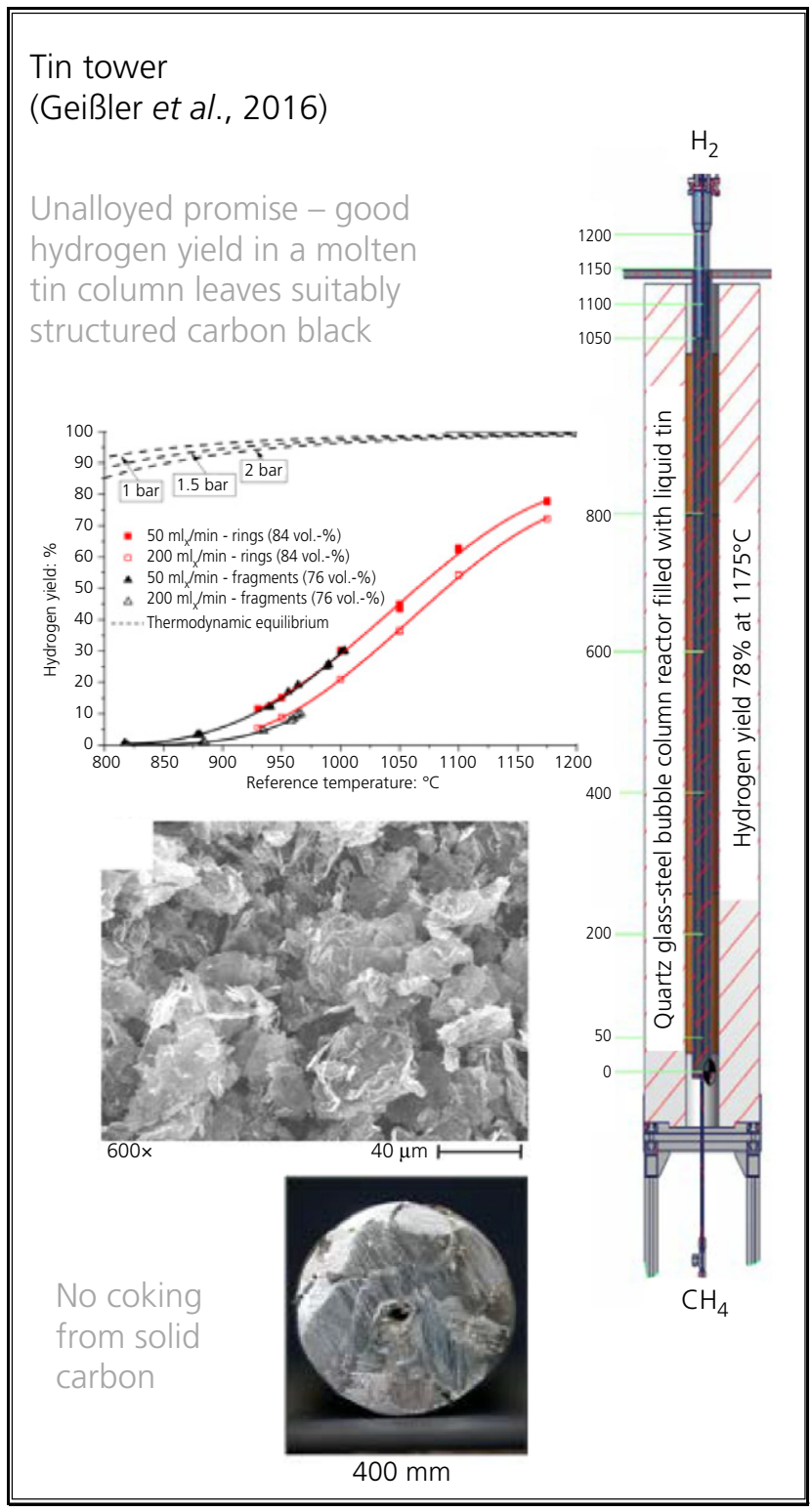

Figure 1. Natural gas is heated in a molten metal, bubbler column where it dissociates into hydrogen and carbon (Geißler et al., 2016) 
of carbon capture where both the product (hydrogen, $\mathrm{H}_{2}$ ) and by-product (carbon, $\mathrm{C}$ ) have utility. The idea is simple, to cheaply split natural gas $\left(\mathrm{CH}_{4}\right)$ into its elements using free heat. A key hurdle is to prevent carbon micro-particles from coking up the process (Abánades et al., 2012). By avoiding carbon dioxide this is carbon capture with the potential for utilisation, or CCU.

In 1966, early pyrolisers used a catalytic fluidised bed to split methane. Revived by the EU, the 2006 SOLHYCARB project (Rodat et al., 2010), investigated the use of solar heat. Promising hydrogen yield and costs spurred further work. A breakthrough in the latest study, DECARGAS, has German industry intrigued ('Tin Tower'). Hot metal pyrolysis can deliver competitive costs and a coke-free, high yield of hydrogen (Geißler et al., 2016).

Thus, there are three routes to hydrogen: reforming (cheap but hobbled by its carbon dioxide burden); electrolysis (still expensive and a problem for arid regions); pyrolysis (unproven at scale). Pyrolysing heat could derive from two sources: ohmically, by way of excess renewable power, or thermally, from concentrated solar energy or possibly fusion. Temperatures above $1000^{\circ} \mathrm{C}$ work best. Many locations across the globe meet the prerequisites: natural gas reserves, solar heat or renewable power ('Hydrogen Hot Spots'). Plant sizes could vary, from vast multi-megawatt systems right down to local, fuelling station-sized hydrogen refilling points. If viable, coal is also a long-term source of carbon (Figure 2).
Bill Gates backed Heliogen (Figure 3) a solar concentrating array that uses artificial intelligence to attain temperatures high enough to make cement or directly split water. It could be used to split methane. Australia, Russia and Canada are well endowed with gas. Huge Himalayan solar potential could serve India, Pakistan, Bangladesh and China, and, at night, molten salt heat stores can keep solar plants on. Sand-sourced regenerated silicon is a way to transport hydrogen. In addition, plasma pyrolysis (Schneider et al., 2020) is another promising route to hydrogen.

\section{Not so black}

Carbon black, the co-product of pyrolysis, has high value. If high-grade carbon is produced, the applications are manifold: in grid-scale battery electrodes, steelmaking with CCS, fibres, tyres and - the prize - industrial graphene. Would the carbon be stored? In Russia, mountains of sulfur have not been burnt because the fumes are noxious, the effects are local but transient and the yellow piles may have uses in future batteries. For carbon, the choice is starker: when not burnt, irredeemable, global consequences are avoided if the carbon black is used in a circular economy.

\section{Integrated action}

Is electricity with batteries the future? Not without hydrogen. To navigate inter-seasonal power demand without large-scale hydrogen production and storage would be perilous to energy

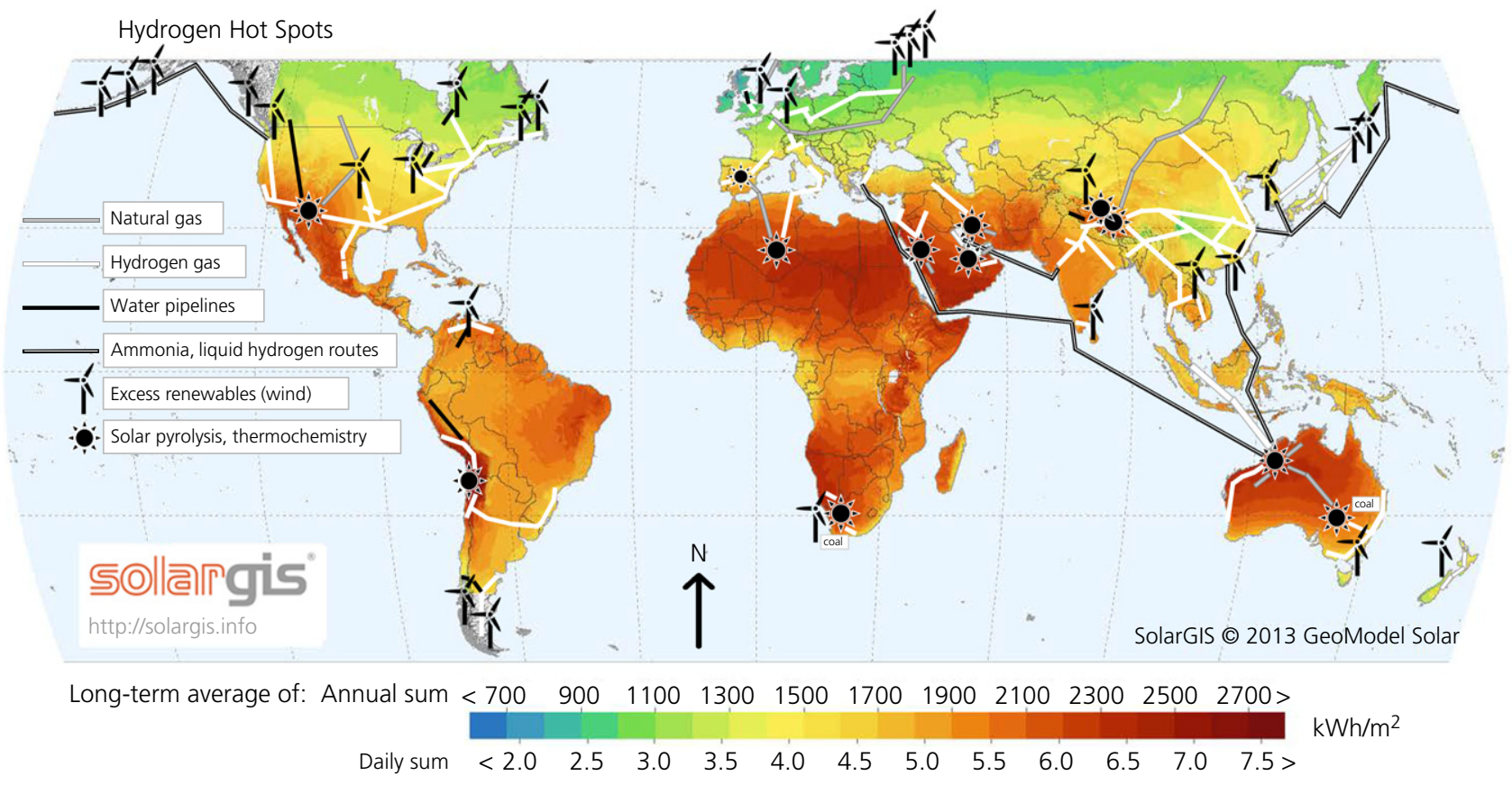

Figure 2. Notional hydrogen scenario, 2040 (map: adapted from The World Bank, Solargis) 


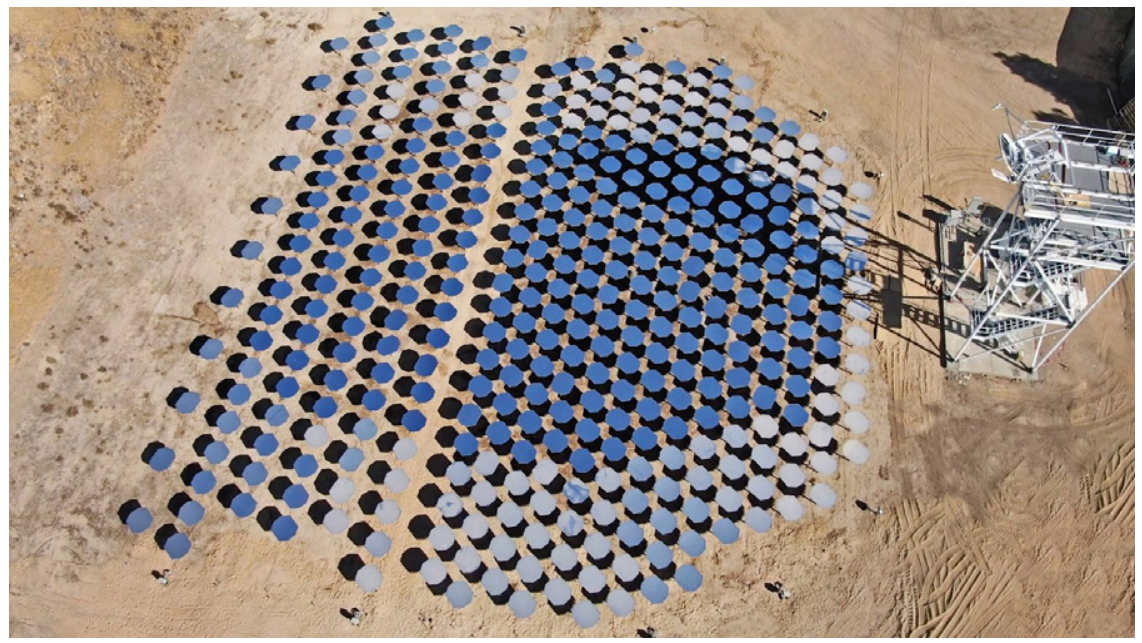

Figure 3. Renewable energy-rich regions could make hydrogen from natural gas without producing carbon dioxide (image: Heliogen)

security. Hydrogen is already a major global industry. However, an Achilles heel limits its future in clean energy: hydrogen must divorce itself from its absolute need for carbon capture and storage. In the authors' opinion, with few exceptions - one is Equinor's $\mathrm{H} 2 \mathrm{H}$ project - carbon dioxide is a troublesome byproduct. Conventional thinking supposes that natural gas reforming with CCS is best since, apparently, it is the cheapest option. Yet such studies omit to show where enough carbon dioxide storage sites exist given the apparent resistance of the public to carbon capture; they simply do not trust it (Whitmarsh et al., 2019). Hydrogen, the authors submit, should mainly be 'white' or 'green' - derived from plentiful natural gas using pyrolysis, or from renewable power using electrolysis.

In one area, perhaps, CCS has a niche future - by way of the direct air capture of carbon dioxide for synthesis (with clean hydrogen) into jet fuel. It is only acceptable to use the atmosphere if the irksome carbon dioxide debt is paid upfront, in full. However, hydrogen-fuelled aircraft, like the Airbus ZEROe, could be a cheaper option in the long run.

The technical innovations outlined here have the potential to bring a sea of hydrogen into play, enabling an energy transition to proceed on the titanic scale required. The next steps are crucial. The fossil fuel industry has a once-in-a-lifetime opportunity to take the lead and re-write the clean energy narrative. Extending hydrogen's role requires a combination of trust, policy clarity and billion-dollar, industrial-scale deployments. The clinching arguments are about energy integration and local-scale action. A top-down conversion of a gas grid today is unthinkable: the change must be bottom up. Pyrolysis would drive the use of valuable gas assets through a step-by-step conversion to hydrogen, while integrating renewable energy, storage and fuel cells.

\section{UN climate change conference of the parties (COP26)}

In the UK, some big projects are already in play, for example Leeds-H21, Teeside Hydrogen and HyNet, not to forget the $\mathrm{H} 2 \mathrm{H}$ venture in Hull. With coronavirus recovery plans being hotly debated across Europe, hydrogen is emerging as a frontrunner. The UK must seize the initiative that its presidency of the vital COP26 climate conference provides. With co-host Italy's backing, and the impetus of a new US administration, the UK must champion clean hydrogen and present a vision and firm plans.

Specifically, the hosts need to lead international negotiations to achieve a collaborative, open-source, clean hydrogen development plan. Everyone wins when patents are pooled; that applies to hydrogen as much as it does to vaccines. The UK's hydrogen projects need to be funded at scale. The fossil fuel companies would be expected to take a leading role here under the intense gaze of international scrutiny. Trust is vital if the financial, technical and physical resources needed are to be tapped. Alok Sharma, the UK minister in charge of COP26, already has the headlines. The 2021 climate conference is all about the energy transition, clean transport and the finance needed to make it all happen.

\section{Declaration of interests}

Richard Clarke has no interests in hydrogen pyrolysis projects or investments. Ortec Finance does not invest in capital 
projects. Alberto Abánades has been involved for several decades in decarbonisation research, by applying technologies ranging from nuclear and solar to methane pyrolysis.

Note: the authors label pyrolytic hydrogen 'white' hydrogen. Elsewhere it has been called 'turquoise' or 'blue-green'. From the authors' perspective, only electrolytic hydrogen can be a shade of green. It is the only form of hydrogen that is both clean and sustainable

\section{REFERENCES}

Abánades A, Rubbia C and Salmieri D (2012) Technological challenges for industrial development of hydrogen production based on methane cracking. Energy 46(1): 359-363.

ClientEarth (2021) Accountability Emergency - A Review of UK-listed Companies' Climate Change-related Reporting (2019-20). ClientEarch, London, UK.

Geißler T, Abánades A, Heinzel A et al. (2016) Hydrogen production via methane pyrolysis in a liquid metal bubble column reactor with a packed bed. Chemical Engineering Journal 299: 192-200.

Henderson K, Pinner D, Rogers M et al. (2020) Climate math: what a 1.5-degree pathway would take. McKinsey Quarterly Magazine, 30 April.

Lewis M. (2020) Why we may have already seen the peak in oil demand. Financial Times, 17 April.
Meinshausen M, Meinshausen N, Hare W et al. (2009) Greenhouse-gas emission targets for limiting global warming to $2^{\circ} \mathrm{C}$. Nature 458(7242): 1158-1162.

Nuttall WJ and Bakenne A (2020) Fossil Fuel Hydrogen. Springer Nature Switzerland AG, Cham, Switzerland, https://doi.org/10. 1007/978-3-030-30908-4.

Rathi A (2018) The EU has spent nearly $\$ 500$ million on technology to fight climate change-with little to show for it. Quartz, 23 October.

Resources Radio (2020) Going Deep on Carbon capture, Utilization and Storage (CCUS), with Julio Friedmann. Resources for the Future, Washington, DC, USA.

Rodat S, Abánades S, Sans JL and Flamant G (2010) A pilot-scale solar reactor for the production of hydrogen and carbon black from methane splitting. International Journal of Hydrogen Energy 35(15): 7748-7758.

Sarsfield-Hall R and Under B (2019) Hydrogen From Natural Gas - the Key to Deep Decarbonisation. Pöyry Management Consulting, Oxford, UK.

Schneider S, Bajohr S, Graf F and Kolb T (2020) State of the art of hydrogen production by way of pyrolysis of natural gas. ChemBioEng Reviews 7(5): 150-158.

UK Government (2020) UK's Net Zero 2050 plan. See https://www.gov. uk/government/news/uk-sets-ambitious-new-climate-target-aheadof-un-summit (accessed 25/05/2021).

Whitmarsh L, Xenias D and Jones CR (2019) Framing effects on public support for carbon capture and storage. Palgrave Communications 5: article 17, https://doi.org/10.1057/ s41599-019-0217-x.

\section{How can you contribute?}

To discuss this briefing, please email up to 500 words to the editor at journals@ice.org.uk. Your contribution will be forwarded to the author(s) for a reply and, if considered appropriate by the editorial board, it will be published as discussion in a future issue of the journal.

Proceedings journals rely entirely on contributions from the civil engineering profession (and allied disciplines). Information about how to submit your paper online is available at www.icevirtuallibrary.com/page/authors, where you will also find detailed author guidelines. 